\title{
The Relation of Multiple Intelligences and Spatial Perception with Performance in Geography Education
}

\author{
Aikaterini Klonari and Anna Aikaterini Likouri \\ University of the Aegean, Mytilene/Greece·aklonari@geo.aegean.gr
}

Short paper

\begin{abstract}
This pilot research was conducted in order to examine the impact of students' and teachers' multiple intelligences and spatial perception on students' performance in geography, and their attitude towards the lesson. The sample was 86 students and 4 teachers in the $6^{\text {th }}$ grade from both a pilot school and a traditional school in Athens. In this paper we present the results from the survey (validated and evaluated for their reliability), which indicated that: 1) There is inefficient geographic knowledge, 2) Most students seem to have lowly developed spatial thinking abilities. In a spatial perception test, they only demonstrated high records in the questions concerning the plan views and the orientation, 3) Geography is considered as a less important subject, 4) The majority of students and teachers had moderate or negative attitudes towards geography, 5) Children with higher spatial thinking abilities had better performance in geography, 6) Spatial intelligence correlated with all types of intelligence, apart from musical, 7) Statistically, no difference between the students' attitude and spatial thinking was determined based on the type of school.
\end{abstract}

\section{Introduction}

Spatial perception is involved in a series of complex processes such as learning, training, working, and even playing games (RAFI et al. 2005). In this direction, the new geography curricula and cartography have changed with the use of computer technology and the development of spatial thinking. The main purpose of the new curricula is to develop the spatial perception. Maps not only depict the world statically, because the use of digital technology and Geoinformatics is adapting to the new forms of organization and presentation of spatial data. Additionally, teaching based on multiple intelligences theory may be more effective than traditional teaching, since language and mathematics are not the only subjects promoted (YALMANCI \& GOZUM 2013). Consequently, students may perform better in all subjects (OZDEMIR et al. 2006). For this reason, more importance should be given to the theory of multiple intelligences, which can support the individuality of students, and transform learning into an enjoyable process (KORNHABER, FIERROS \& VEENEMA 2004). 
Accordingly, it is considered necessary to examine the impact of multiple intelligences and spatial perception on students' performance, and students' and teachers' attitude towards geography.

\section{Methodology}

The sample was 86 students [47 male $(54,7 \%)$ and 39 female $(45,3 \%)$ ] of sixth grade from two schools in Athens, and their respective teachers ( 2 male, 2 female) aged 28-46 years $($ mean $=37.5)$. All teachers had at least 6 years of teaching experience. The first school participated in a pilot program with extended use of new technologies in learning $(\mathrm{N}=44)$, and the other was a more traditional school $(\mathrm{N}=42)$. The research tools were: a) a test of spatial perception of J. Tsaousi. The test consists of three parts: the first part examines the person's ability to mentally rotate the various shapes, the second part refers to the ability to discern different 3-dimensional shapes from different visual angles (plan views), the third part relates to the individual's ability to perceive and process complex 3-dimensional patterns (refolding items); b) the scale of measurement MI (Multiple Intelligences) of Armstrong, which includes 10 self-report statements for each type of intelligence (linguistic, logical-mathematical, spatial, bodily-kinesthetic, musical, interpersonal, intrapersonal, naturalist); c) a questionnaire with closed and open-ended questions to investigate the attitudes of teachers and students towards geography; and d) a test with geography activities in connection with the spatial perception of students according to the model of Gersmehl and Gersmehl (2007). The test consists of 10 questions in order to evaluate the following spatial abilities: spatial concepts, spatial analogies, spatial hierarchies, spatial groups (regions), spatial patterns, spatial sequences and transitions, spatial comparisons, plan views, and orientation. The research tools were completed in two hours.

\section{Results and Discussion}

First of all we corrected the vague points of the research tools and we adapted the geography activities to the new geography curriculum. Moreover, in the pilot study we observed a lack of geographical knowledge. More specifically, the students of the sample scored an average of 5,42 (S.D=1,73) out of 10 in a geography test. The same lack of knowledge was observed in earlier studies (KATSIKIS 2001, KLONARI 2012).

In the geography test, high records were only observed in the plan views and the orientation. Furthermore, the students had especial difficulty in spatial sequences, spatial analogies and spatial comparisons. Furthermore, in the spatial perception test, the highest score was observed in "plan views" (average $=4.93, \mathrm{SD}=2.31$ ), a moderate score was observed in the "intellectual constructs spins" (average $=4.43, \mathrm{SD}=2.40$ ), and the lowest score was observed in the "refolds objects" (average $=3.62, \mathrm{SD}=1.76$ ). The display of space through digital technology (3D maps, satellite images, GIS, etc.) helps students to understand it better and develop special skills. The lack of digital technology and the sole use of static map display, are at fault for these results (LEE \& BEDNARZ 2009).

Students with the highest spatial perception performed better in geography. These students had higher total spatial perception $(r=0,45, p<0,01)$ and more specifically they showed high 
records in "plan views" $(\mathrm{r}=0,37, \mathrm{p}<0,01)$ and "intellectual constructs spins" $(\mathrm{r}=0,36$ $\mathrm{p}<0,01)$. This demonstrates the necessity to teach geography by regularly using activities that strengthen the spatial thinking abilities.

The lesson of geography is less popular and it is considered less important from both teachers and students. For these reasons it occupies the last position in their preferences. This corresponds to the findings of other researchers (KATSIKIS 2001, KLONARI 2004), which showed the stagnation of geography in greek schools.

Only one quarter of the students $(26,7 \%)$ had a very positive attitude to the subject, while the rest $(73,3 \%)$ had a moderate or negative attitude towards geography. A similar attitude was observed from the teachers, who, according to studies (KLONARI \& KOUTSOPOULOS 2005), affect the performance of their students. Nevertheless, this result needs further examination, as only 4 teachers participated in this pilot study. We should emphasize that 3 out of 4 teachers mentioned that the main obstacle in teaching geography is the lack of appropriate educational material. $12,8 \%$ of students reported the same problem. In addition, $8,1 \%$ of the students find the way in which geography is taught boring and less motivating. This confirms the findings of the literature (KLONARI 2004).

Nowadays, outdated methods of teaching are still used, although it is commonly known that the use of new technologies makes the geography lesson more interesting and fascinating. As a result, a reduced interest for the subject is observed, negatively affecting students' performance (SHANGHNESSY \& HALADYNA 1985).

Furthermore, we noticed that the spatial intelligence has statistically significant correlations with all types of intelligence except musical $(r=0,16, p>0,05)$. More specifically:

- $\quad$ verbal-linguistic $(\mathrm{r}=0,36, \mathrm{p}<0,01)$,

- $\quad$ logical-mathematical $(\mathrm{r}=0,48, \mathrm{p}<0,01)$,

- $\quad$ bodily-kinesthetic $(\mathrm{r}=0,55, \mathrm{p}<0,01)$,

- $\quad$ interpersonal $(\mathrm{r}=0,22, \mathrm{p}<0,05)$,

- $\quad$ intrapersonal $(\mathrm{r}=0,48, \mathrm{p}<0,01)$,

- $\quad$ naturalistic $(\mathrm{r}=0,49, \mathrm{p}<0,01)$.

This means that the spatial perception may be developed not only through geography and mathematics, but also through other subjects, like language teaching, etc.

The educational background of fathers seems to affect the average of $2 \mathrm{D}$ spatial perception (plan views), and the general performance of students in the subject of geography. In particular, students whose fathers received higher education (average $=5.58, \mathrm{SD}=2.57$ ) perform $(\mathrm{t}(84)=-1,99, \mathrm{p}<0,05)$ better than those students whose fathers have primary education. Moreover, students with highly educated fathers score higher grades in geography (average $=9.39, \mathrm{SD}=0.70)[\mathrm{t}(84)=-2,12, \mathrm{p}<0,05]$, than the students whose fathers had only finished high school studies (average $=8.97, \mathrm{SD}=0.95$ ).

These findings confirm the research of GANZACH (2000), which indicated the correlation between school performance and parents' educational background. Especially, in this research, students' school performance in geography is strongly affected by their fathers. This finding needs deeper examination, too. Finally, no statistically important difference between the two types of school (pilot and traditional) and students' attitude and spatial thinking was observed. 


\section{Conclusions}

In this research, no significant difference between the two schools, neither in the attitude of the students, nor in the development of spatial perception was determined. These findings give us a small insight into the implementation of the new geography curriculum in schools, but the sample in this study was not representative, so we were not able to come to final conclusions. Of course, despite the obstacles of the survey, the results indicated a lack existed in students' spatial perception and geographic knowledge. Moreover, there was a negative attitude towards the subject of geography despite the teachers' training for the new curricula (in pilot school) and the existing new digital educational material. Certainly, all abovementioned aspects should be examined thoroughly in the entire sample of pilot schools throughout Greece. Furthermore, it is proposed to correlate the spatial perception and multiple types of intelligence with the teaching of all subjects' in $6^{\text {th }}$ grade of Primary Education.

\section{References}

GANZACH, Y. (2000), Parents' Education, cognitive ability, educational expectations and educational attainment: Interactive effects. British Journal of Educational Psychology, 70, 419-441.

Gersmehl, F. \& GersmeHL, A. (2007), Spatial Thinking by Young Children: Neurologic Evidence for Early Development and "Educability". Journal of Geography, 106, 181191. National Council for Geographic Education.

KATSIKIS, A. (2001), Geography and geographical education: Reason of crisis- Regenerative intervention proposal. Geographies, 2, 15-29 (in Greek).

KLONARI, A. (2004), Teachers', in Primary and Secondary Education, points of view towards the subject of Geography. In: Proceedings of the 7th Panhellenic Geographical Conference of the Greek Geographical Society, II, Mytilene, 602-610 (in Greek).

KLONARI, A. (2012), Primary School Pupils' Ability to Use Aerial Photographs and Maps in the Subject of Geography. European Journal of Geography, 3(2), 42-52.

Klonari, A. \& Koutsopoulos, K. (2005), Primary and Secondary Educators' Attitudes on School Geography. In: DONERT, K. \& ChArZYNSKI, P. (Ed.), Changing Horizons in Geography Education, 151-155.

Kornhaber, M. L., Fierros, E. G. \& Veenema, S. (2004), Multiple intelligences: Best ideas from research and practice. Allyn \& Bacon Publishers, Needham Heights, MA.

LEE, J. \& BEDNARZ, R. (2009), Effect of GIS Learning on Spatial Thinking. Journal of Geography in Higher Education, 33(2), 183-198.

OzDEMIR, P., GUNEYsu, S. \& TeKKAYA, C. (2006), Enhancing learning through multiple intelligences. Journal of Biological Education, 40 (2), 74-78.

RAFI, A., ANUAR, K., SAMAD, A., HAYATI, M. \& MAHADZIR, M. (2005), Improving spatial ability using a Web- based Virtual Environment. Autom. in Construction, 14, 707-715.

Shaughnessy, J. M., Halabyna, T. M. (1985), Research on student attitude toward the social studies. Social Education, 49, 692-695.

YALMANCI, S. G. \& GozUM, A. I. (2013), The effects of multiple intelligence theory based teaching on students' achievement and retention of knowledge. International journal on New Trends in Education and Their Implications, 4 (3), 27-36. 